\title{
Physiologic and pathologic functions of the NPP nucleotide pyrophosphatase/ phosphodiesterase family focusing on NPP1 in calcification
}

\author{
Robert Terkeltaub \\ University of California School of Medicine, VA Medical Center, 3350 La Jolla Village Drive, San Diego, \\ CA, USA
}

Received 1 November 2005; accepted in revised form 14 November 2005; Published online 1 June 2006

Key words: ANK, ANKH, cartilage, inorganic phosphate, inorganic pyrophosphate, osteopontin

\begin{abstract}
The catabolism of ATP and other nucleotides participates partly in the important function of nucleotide salvage by activated cells and also in removal or de novo generation of compounds including ATP, ADP, and adenosine that stimulate purinergic signaling. Seven nucleotide pyrophosphatase/phosphodiesterase NPP family members have been identified to date. These isoenzymes, related by up conservation of catalytic domains and certain other modular domains, exert generally non-redundant functions via distinctions in substrates and/or cellular localization. But they share the capacity to hydrolyze phosphodiester or pyrophosphate bonds, though generally acting on distinct substrates that include nucleoside triphosphates, lysophospholipids and choline phosphate esters. $\mathrm{PP}_{\mathrm{i}}$ generation from nucleoside triphosphates, catalyzed by NPP1 in tissues including cartilage, bone, and artery media smooth muscle cells, supports normal tissue extracellular $\mathrm{PP}_{\mathrm{i}}$ levels. Balance in $\mathrm{PP}_{\mathrm{i}}$ generation relative to $\mathrm{PP}_{\mathrm{i}}$ degradation by pyrophosphatases holds extracellular $\mathrm{PP}_{\mathrm{i}}$ levels in check. Moreover, physiologic levels of extracellular $\mathrm{PP}_{\mathrm{i}}$ suppress hydroxyapatite crystal growth, but concurrently providing a reservoir for generation of pro-mineralizing $\mathrm{P}_{\mathrm{i}}$. Extracellular $\mathrm{PP}_{\mathrm{i}}$ levels must be supported by cells in mineralization-competent tissues to prevent pathologic calcification. This support mechanism becomes dysregulated in aging cartilage, where extracellular $\mathrm{PP}_{\mathrm{i}}$ excess, mediated in part by upregulated NPP1 expression stimulates calcification. $\mathrm{PP}_{\mathrm{i}}$ generated by NPP1modulates not only hydroxyapatite crystal growth but also chondrogenesis and expression of the mineralization regulator osteopontin. This review pays particular attention to the role of NPP1catalyzed $\mathrm{PP}_{\mathrm{i}}$ generation in the pathogenesis of certain disorders associated with pathologic calcification.
\end{abstract}

Abbreviations: ANK - protein product of the murine ankylosis disease susceptibility gene; CPPD - calcium pyrophosphate dihydrate; CILP - cartilage intermediate layer protein; HA - hydroxyapatite; IIAC - Idiopathic Infantile Artery Calcification; MV - matrix vesicles; NPP - nucleotide pyrophosphatase/phosphodiesterase; OPLL - ossification of the posterior longitudinal ligament; $\mathrm{SMC}$ - smooth muscle cells; $\mathrm{SNP}$ - single nucleotide polymorphism; TNAP - tissue nonspecific alkaline phosphatase

\section{Introduction}

The extracellular catabolism of ATP and other nucleotides by coordinated ecto-enzymes mediates nucleotide salvage by activated cells and also drives removal or de novo generation of compounds including ATP, ADP, and adenosine that stimulate purinergic signaling [1-3]. This subject is reviewed in depth by Stefan et al. in this special issue of the journal. Among the many enzymes participating in nucleotide catabolism are certain nucleotide pyrophosphatase/phosphodiesterase (NPP) family members, including NPP1, the principal subject of this review. Seven NPPs have been identified to date (Figure 1) [4]. These isoenzymes, related by $24 \%-60 \%$ conservation in catalytic domains [ 4 ] and by

Correspondence to: Robert Terkeltaub, Rheumatology Section, San Diego Veterans Affairs Medical Center, San Diego, CA 92161, USA. Tel: +1-8585528585; Fax:+1-858-5527425; E-mail: rterkeltaub@ucsd.edu conservation of certain other modular domains, exert generally non-redundant functions via distinctions in substrates and/or subcellular localization. For example, the type II transmembrane ecto-enzymes NPP1 (PC-1, npps) and NPP3 (B10, CD203c, PD-1 $\beta$, gp130 ${ }^{\mathrm{RB} 13-6}$ ), which exist as disulfide-bonded homodimers in membranes, and whose extracellular domains can be proteolytically liberated into secreted forms, exert nucleoside triphosphate pyrophosphohydrolase (NTPPPH) activity that generates $\mathrm{PP}_{\mathrm{i}}$ from ATP and other nucleoside triphosphates, as discussed below, NPP1 and NPP3 both subserve other functions by alkaline $\mathrm{pH}$ optimum nucleotide phosphodiesterase activities [5-8]. However, the dileucine motif in the cytosolic tail of NPP1 (but not NPP3) mediates differential subcellular localization to the basolateral and apical plasma membrane, respectively, in polarized cell types [5]. 
Isoenzyme

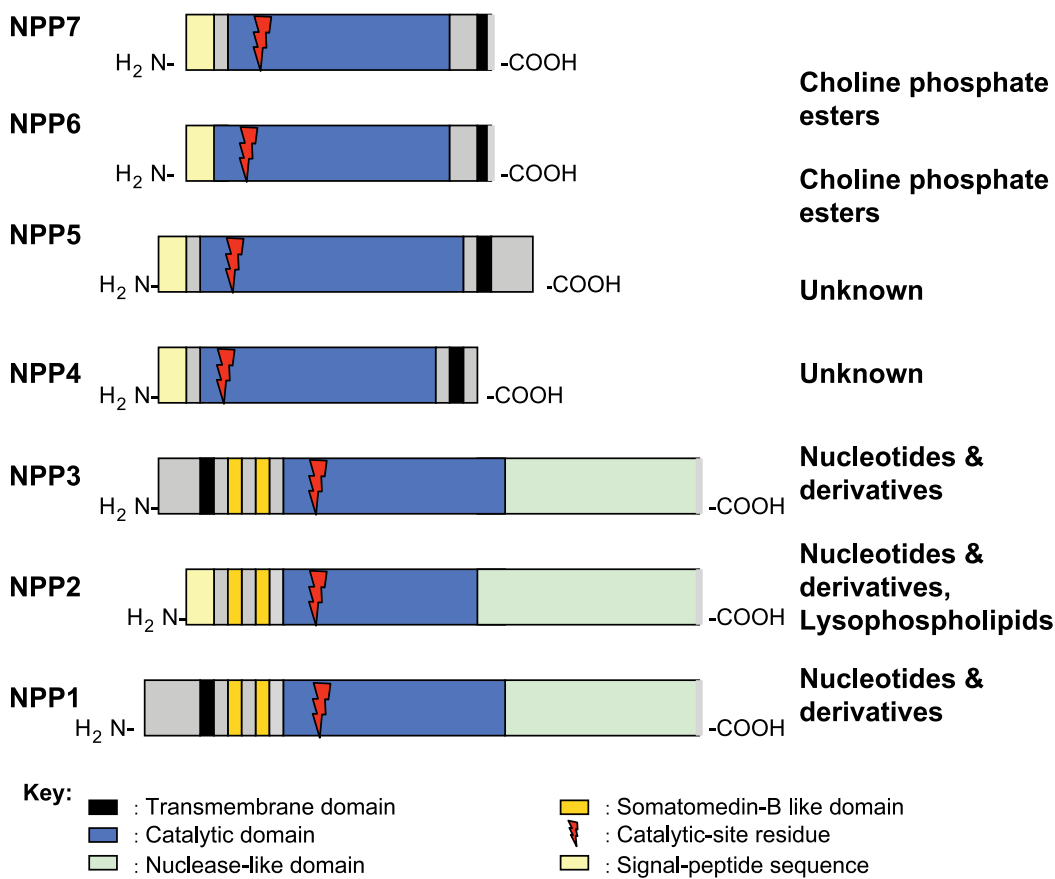

\section{Typical}

Substrates

\section{Choline phosphate \\ Choline phosphate}

Figure 1. General Structural Features of NPP family members. The schematic highlights related structural features of NPPs 1-7, as discussed further in the text.

NPP2 (autotaxin, PD-1 $\alpha$ ), though very similar to NPP1 and NPP3 in structural organization (Figure 1), is synthesized as a pro-enzyme and further processed to be a secretory molecule (4.9). NPP2 lysophospholipase D specific activity is much higher than that of other NPP family members and specific activity as a nucleotide pyrophosphatase/phosphodiesterase much lower than that of NPP1 and NPP3 $[10,11]$. Correspondingly, we have observed that direct expression of NPP2 did not increase extracellular $\mathrm{PP}_{\mathrm{i}}$ in chondrocytes, under conditions in which NPP2 did stimulate both alkaline phosphatase and increased calcification [12]. NPP6 and the intestinal enzyme NPP7 (Figure 1) exert lysophospholipase C or choline phosphate esterase activities [4]. The secretion of NPP2 by multiple tissues, and NPP2 accumulation in extracellular fluids, allows NPP2, in large part via lysophospholipase D activity, to exert a variety of biologically significant effects on cell growth, differentiation, adhesion, and migration, translated into functional effects in angiogenesis, tumor metastasis, and embryonic development [4, 13-15].

Comparative molecular structure-function of NPPs and their substrate specificities were recently reviewed in a thorough and lucid manner [4]. This review focuses on the functions of NPP1 in the regulation of physiologic and pathologic calcification, principally via $\mathrm{PP}_{\mathrm{i}}$ generation from nucleoside triphosphates in tissues (and cells) including cartilage (and chondrocytes), bone (and osteoblasts), and large arteries (and smooth muscle cells (SMCs)).

(n) 
widely spread through NPP1 extracellular domains [23]. Many of these NPP1 mutations, which are mostly in the nuclease-like and catalytic, domains, but also reported in the somatomedin B-like domain, have been established to impair NPP1 catalytic activity $[23,24]$.

Notably, $\mathrm{PP}_{\mathrm{i}}$ serves as reservoir for alkaline phosphatase-catalyzed $\mathrm{P}_{\mathrm{i}}$ generation that is pro-mineralizing, as

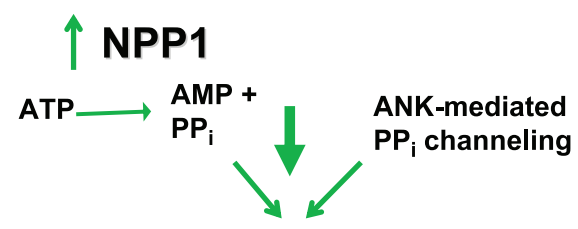

Excess Extracellular $\mathrm{PP}_{\mathrm{i}}$

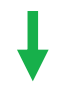

Extracellular Matrix

Saturated with $\mathrm{PP}_{\mathrm{i}}$

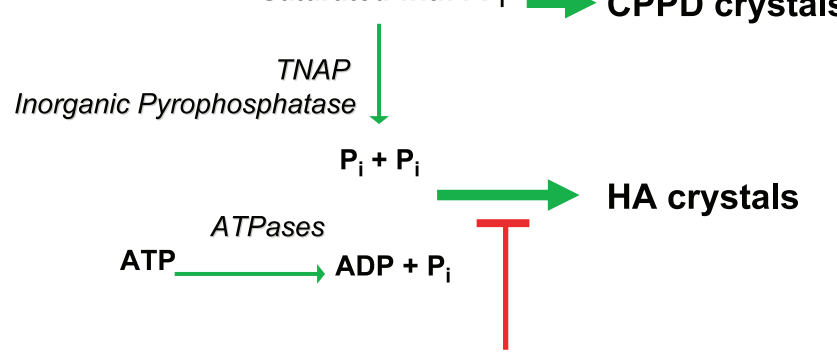

Chondrogenesis - Physiologic $\mathrm{PP}_{\mathrm{i}}$ :

Promotes Osteopontin

Expression and Directly

Regulates HA Crystal

Nucleation and Growth

Figure 2. Proposed NPP1-mediated and $\mathrm{PP}_{\mathrm{i}}$-dependent mechanisms stimulating CPPD and HA crystal deposition in aging and osteoarthritis (OA): Roles of ATP and $\mathrm{PP}_{\mathrm{i}}$ Metabolism and inorganic phosphate $\left(\mathrm{P}_{\mathrm{i}}\right)$ generation in pathologic cartilage calcification. This model presents mechanisms underlying the common association of extracellular $\mathrm{PP}_{\mathrm{i}}$ excess with both CPPD and HA crystal deposition in OA and chondrocalcinosis cartilages, as well as the paradoxical association of extracellular $\mathrm{PP}_{\mathrm{i}}$ deficiency (from defective ANK or PC-1/NPP1 expression) with pathologic calcification of articular cartilage with HA crystals in vivo. Factors driving pathologic calcification are indicated in green and physiologic factors suppressing calcification in red. Excess $\mathrm{PP}_{\mathrm{i}}$ generation in aging cartilages in idiopathic CPPD deposition disease of aging, and in OA cartilages, is mediated in part by marked increases in NTPPPH activity, mediated in large part by the PC-1/NPP1 isoenzyme. In idiopathic chondrocalcinosis of aging and in $\mathrm{OA}$, there are substantial increases in joint fluid $\mathrm{PP}_{\mathrm{i}}$ derived largely from cartilage. NPP1 not only directly induces elevated $\mathrm{PP}_{\mathrm{i}}$ but also matrix calcification by chondrocytes in vitro. Depending on extracellular availability of substrate $\mathrm{PP}_{\mathrm{i}}$ and the activity of pyrophosphatases, the availability of substrate ATP and the activity of ATPases, and other factors such as substantial local $\mathrm{Mg}^{++}$ concentrations, HA crystal deposition, as opposed to CPPD deposition, may be stimulated. In this model, excess extracellular $\mathrm{PP}_{\mathrm{i}}$ also may result from heightened release of intracellular $\mathrm{PP}_{\mathrm{i}}$ via increased $\mathrm{ANK}$ expression in OA and abnormal ANK function in familial chondrocalcinosis, as well as from deficient activity of pyrophosphatases (such as TNAP and possibly inorganic pyrophosphatase) in certain primary metabolic disorders. Also illustrated at the top of this schematic is the role in cartilage calcification in $\mathrm{OA}$ and aging of altered $\mathrm{TGF} \beta$ expression and responsiveness, which drives $\mathrm{PP}_{\mathrm{i}}$ generation and release mediated via NPP1 and ANK, and diminished responsiveness to IGF-I, which normally suppresses elevation of chondrocyte extracellular $\mathrm{PP}_{\mathrm{i}}$. illustrated by osteopenia in long bones of NPP1 deficient mice $[27,28]$. As such, $\mathrm{PP}_{\mathrm{i}}$ generation can both suppress and promote HA crystal deposition, depending on relative tissue levels of NPP1 and alkaline phosphatase (Figure 2) [16-21, 27, 28]. The capacity of chondrocytes to produce copious extracellular $\mathrm{PP}_{\mathrm{i}}$ is particularly double edged, as it is directly promotes calcium pyrophosphate dihydrate (CPPD) crystal deposition (Figure 2). Depending on cartilage ATP and $\mathrm{PP}_{\mathrm{i}}$ concentrations, and the level of activity of $\mathrm{P}_{\mathrm{i}}$-generating ATPases and pyrophosphatases, NPP1 excess promotes both HA and CPPD crystal formation by articular chondrocytes [12, 29-31], an event that commonly occurs in the joint in human aging and osteoarthritis (OA) [32].

$\mathrm{PP}_{\mathrm{i}}$ appears to directly regulate expression of certain genes (including inductive effects first described by us for osteopontin and MMP-13 expression and suppressive effects on Sox9 expression)[18, 33-35]. $\mathrm{PP}_{\mathrm{i}}$ regulates certain cellular differentiation and functions including protein synthesis [19], chondrogenesis [35], and promineralizing chondrocyte maturation to terminal hypertophic differentiation transduced partly by Pit-1 mediated $P_{i}$ uptake [36]. Such effects of $P_{P_{i}}$ are analogous to effects of not only $\mathrm{P}_{\mathrm{i}}$ [37, 38] but also bisphosphonate $\mathrm{PP}_{\mathrm{i}}$ analogues $[39,40]$. It is not clear in which subcellular compartments $\mathrm{PP}_{\mathrm{i}}$ could act to carry out these effects and what contributions $\mathrm{P}_{\mathrm{i}}$ derived from $\mathrm{PP}_{\mathrm{i}}$ makes in these activities of $\mathrm{PP}_{\mathrm{i}}$.

Mammalian extramitochondrial mechanisms for $\mathrm{PP}_{\mathrm{i}}$ production, degradation, and transport were recently reviewed in depth [19]. In cells such as osteoblasts and chondrocytes that normally express NPP1 relatively robustly, NPP1 and NPP3 increase intracellular $\mathrm{PP}_{\mathrm{i}}$, suspected to be in large part in the lumen of the ER and Golgi $[12,16,31]$. Critical to support of extracellular $\mathrm{PP}_{\mathrm{i}}$ is apparent direct $\mathrm{PP}_{\mathrm{i}}$ transport by the multiple-pass transmembrane protein ANK [41], which makes a major contribution to moving to the movement into the extracellular space of intracellular $\mathrm{PP}_{\mathrm{i}}$, including the fraction of intracellular $\mathrm{PP}_{\mathrm{i}}$ generated by NPP1 [34].

\section{NPP1 and PP $P_{i}$ metabolism in cartilage and bone}

Extracellular $\mathrm{PP}_{\mathrm{i}}$ rises markedly in articular cartilage in direct association with aging and $\mathrm{OA}$, and resultant matrix supersaturation with $\mathrm{PP}_{\mathrm{i}}$ and cartilage matrix abnormalities that alter the solubility product of $\mathrm{PP}_{\mathrm{i}}$ and $\mathrm{Ca}^{2+}$ promote calcification [42]. Physiologic chondrocyte $\mathrm{PP}_{\mathrm{i}}$ metabolism is regulated in part by growth factor and cytokine regulatory effects on chondrocyte NPP1 expression. Interruption in regulatory checks and balances on articular cartilage $\mathrm{PP}_{\mathrm{i}}$ metabolism appears to occur in aging and diseases including OA. For example, the chondrocyte growth factor TGF $\beta$ induces both NPP1 expression and elevation of extracellular $\mathrm{PP}_{\mathrm{i}}[12,31,43]$. The capacity of TGF $\beta$ to increase cartilage NPP activity and extracellular $\mathrm{PP}_{\mathrm{i}}$ levels directly correlates with donor age [12, 31, 44]. The TGF $\beta$-stimulated cellular program for chondrocyte 
extracellular $\mathrm{PP}_{\mathrm{i}}$ elevation includes substantial increases in ATP generation [45] and stimulation of NPP1 movement to the plasma membrane [12, 31].

Osteoblasts and chondrocytes have particularly high levels of both NPP1 expression and NPP specific activity $[19,46,47]$. Moreover, chondrocyte NPP activity increases in direct condordance with cartilage $\mathrm{PP}_{\mathrm{i}}$ generation (to an average of double normal levels) in a donor age-dependent manner [47]. The age-dependent increases in NPP activity are directly linked to CPPD crystal deposition disease [47]. Upregulation of NPP1 but not NPP3 is associated with calcification by chondrocytic cells in situ and in vitro [12, 31]. Unlike NPP1, which regulates both intracellular and extracellular $\mathrm{PP}_{\mathrm{i}}$ in chondrocytes, NPP3 appears to principally regulate only intracellular $\mathrm{PP}_{\mathrm{i}}[12,31]$.

Chondrocyte mitochondrial dysfunction associated with spontaneous $\mathrm{OA}$ in Hartley guinea pig knees promotes ATP depletion [48]. Significantly increased NPP activity and extracellular $\mathrm{PP}_{\mathrm{i}}$ develop concurrent with the ATPdepleted state [48]. Hence, increased ATP-scavenging by energy-depleted chondrocytes likely promotes extracellular $\mathrm{PP}_{\mathrm{i}}$ excess in human $\mathrm{OA}$ and aging cartilages.

A series of studies from one research group erroneously reported that cartilage intermediate layer protein (CILP), an interterritorial and pericellular matrix constituent in cartilage with a molecular weight similar to that of NPP1, was an NPP family member, even though there was no structural similarity of CILP to NPP family members [49-51]. We refuted this work [52], and in so doing, we demonstrated that increased expression of one of 2 CILP isoforms (CILP-1) in aging cartilage interferes with the regulatory effects of IGF-I on $\mathrm{PP}_{\mathrm{i}}$ metabolism, thereby promoting increased extracellular $\mathrm{PP}_{\mathrm{i}}$ and cartilage calcification.

\section{NPP1 and PP $_{i}$ metabolism in pathologic soft tissue calcification syndromes and pivotal role of osteopontin depletion}

Consistent with the apparent co-dependent function of ANK and NPP1 to raise extracellular $\mathrm{PP}_{\mathrm{i}}$ [34] is the remarkable similarity in the consequences of deficient $\mathrm{ANK}$ and PC-1 function in vivo. Both NPP1 deficient mice and mice homozygous for a natural C-terminal ANK mutant that appears to incapacitate $\mathrm{ANK} \mathrm{PP}_{\mathrm{i}}$ transport function (ank/ank mice) spontaneously develop a progressive phenotype of pathologic soft tissue calcification that with increasing age comes to include perispinal ligament hyperostosis, periarticular calcification leading to ossific fusion of peripheral joints, extensive articular cartilage degeneration associated with HA deposits, and large artery calcification $[22,35]$. The initial implication of NPP1 deficiency in spontaneous pathologic soft tissue calcification was in 'tiptoe walking' ttw/ttw mice, which are homozygous for a spontaneous nonsense mutation that encodes for a stop codon at tyrosine 568 , a position $3^{\prime}$ of the NPP1 catalytic site [20]. It is not yet known if NPP1 expression is depressed or absent in $t t w / t t w$ mice, or if the ttw mutation, like many of the NPP1 mutations seen in humans with GACI, critically impairs catalytic activity, putatively by interfering with substrate binding.

Human ossification of the posterior longitudinal ligament (OPLL), a form of spontaneous pathologic perispinal ligament calcification common in Japanese subjects, has been linked with certain SNPs in the NPP1 gene [53-55]. It will be of interest to see if the implicated NPP1 sequence variants affect NPP1 expression and function. Interestingly, the inflammatory cytokine IL-1 depresses NPP1 expression, NPP activity, and extracellular $\mathrm{PP}_{\mathrm{i}}$ in chondrocytes [43]. In this context, a $\sim 30 \%$ depression in serum NPP activity is seen in males with the chronic inflammatory disease ankylosing spondylitis [56], a condition that, like OPLL and spinal alterations in NPP1deficient mice, associated with ankylosing intervertebral soft tissue calcification.

Interestingly, periarticular and bone abnormalities are far more substantial and progressive in NPP1-deficient mice than in NPP1-deficient humans with GACI. Conversely NPP1 deficient mice [35] do not demonstrate the severe myointimal proliferative changes seen in arteries in human GACI $[24,25]$. We speculate that the relatively high level of normal serum $\mathrm{P}_{\mathrm{i}}$ in mice compared to humans ( $\leq 8$ vs. $\leq 4.5 \mathrm{mg} / \mathrm{dL}$, respectively) [46] plays a major role in determining these phenotypic distinctions. In this context, high dietary $\mathrm{P}_{\mathrm{i}}$ worsens pathologic calcification in NPP1 null mice [46]. Conversely, low serum $P_{i}$ induced by crossbreeding with PHEX null mice is associated with correction of pathologic artery and soft tissue calcification in both NPP1 null and ank/ank mice [46].

Unlike cultured cells of ank/ank mice, NPP1-deficient cells demonstrate low intracellular as well as extracellular $\mathrm{PP}_{\mathrm{i}}$ levels [18]. Thus, the common basis for the remarkably similar hypermineralizing phenotypes seen in ank/ank mice and in NPP1 null mice (and the pathologic calcification seen in the human NPP1 deficiency state GACI) appears to rest in depression of extracellular $\mathrm{PP}_{\mathrm{i}}$. Furthermore, the marked depletion of extracellular $\mathrm{PP}_{\mathrm{i}}$ and of osteopontin, the rapid, extensive calcification by both NPP1-/- and ank/ank osteoblasts in culture are corrected by soluble NPP1, reinforcing a central role of NPP1 in skeletal PP $_{i}$ and $\mathrm{P}_{\mathrm{i}}$ metabolism and osteopontin expression [18], a notion strongly supported by in vivo studies [21,33].

$\mathrm{P}_{\mathrm{i}}$, mediated by uptake through plasma membrane sodium-phosphate co-transport, stimulates expression of osteopontin, an inhibitor of HA crystal growth and promoter of mineral resorption [37, 38]. As cited above, exogenous $\mathrm{PP}_{\mathrm{i}}$ also induces osteopontin expression [18, 33]. It is not yet clear whether uptake of $P_{i}$ derived from extracellular $\mathrm{PP}_{\mathrm{i}}$ is a major signaling intermediate in this process. Nevertheless, it is remarkable that one HA crystal growth inhibitor $\left(\mathrm{PP}_{\mathrm{i}}\right)$ promotes expression of a second in the form of osteopontin. Because osteopontin knockout mice have relatively mild changes in mineralization in contrast to the marked phenotypic abnormalities in extracellular $\mathrm{PP}_{\mathrm{i}}$-deficient mice, $\mathrm{PP}_{\mathrm{i}}$ clearly higher than osteopontin in the physiologic hierarachy of HA crystal growth inhibitors. 
As previously reviewed [19, 29], NPP1 plays a major role in regulating nucleation of mineral in chondrocyte-, osteoblast-, and apparently artery smooth muscle cellderived secretory bodies released by budding from the plasma membrane and termed matrix vesicles (MVs). The MVs, are enriched in NPP1 and TNAP, whose catalytic domains are predominantly exposed at the external face of MVs. The MVs provide a sheltered environment for initiation of mineral crystal formation in a manner modulated by the concentration of $\mathrm{PP}_{\mathrm{i}}$, though mineral propagation is mediated by other factors, including availability of fibrillar collagen in 'osteoid' to serve as a nidus for calcification with HA [46]. NPP1 is clearly the principal NPP associated with chondrocyte-derived and osteoblast-derived MVs [16, 17, 21, 30, 57]. NPP1 and TNAP exert mutually antagonistic regulatory effects on crystal deposition in MVs, and activity not shared by NPP3 [16]. Cell differentiation and a variety of calciotropic hormones and cytokines (including 1,25 dihydroxyvitamin D3, TGF $\beta$, and IL-1) can regulate the NPP1 content, NPP and alkaline phosphatase activities, $\mathrm{PP}_{\mathrm{i}}$ content, and other compositional features of MVs [29]. However, we have not seen concentrated ANK localization in MVs [33], likely contributing to the observation that correction of pathologic calcification by TNAP deficiency is less marked in ank/ ank than NPP1-/- mice [33].

\section{NPP1 and $P P_{i}$ deficiency states are linked to accelerated chondrogenesis}

Taken together, it is clear that NPP1 and $\mathrm{PP}_{\mathrm{i}}$ physiologically function to prevent calcification of arteries and certain other soft tissues at the level of cell differentiation, and not simply at the level of mineral formation and resorption in the extracellular matrix. Most strikingly, we recently discovered that trans-differentiation of artery SMCs and accelerated intra-arterial chondrogenic differentiation mediated directly by $\mathrm{PP}_{\mathrm{i}}$ depletion promotes spontaneous artery media calcification in NPP1-/- and ank/ank mice [35]. Specifically, we observed that NPP1 deficiency promoted the spontaneous emergence of chondrogenesis from bone marrow stromal cells under noncalcifying conditions. Cultured NPP1-/- aortic SMC preparations and NPP1-/- aortic cells 023060 in situ expressed cbfa1, osteocalcin, and chondrocyte-specific collagens. Osteopontin expression was depressed and procalcifying alkaline phosphatase specific activity and calcification were markedly upregulated in cultured NPP1-/SMCs [35]. In contrast, there was no gross alteration in expression of the physiologic artery calcification inhibitors matrix gla protein and osteoprotegerin in NPP1-/- mouse arterial cells [35]. The capacity of exogenous $\mathrm{PP}_{\mathrm{i}}$ to correct spontaneous chondrogenesis in NPP $1-/-$ bone marrow stromal cells under non-calcifying conditions suggested that extracellular $\mathrm{PP}_{\mathrm{i}}$ deficiency directly promoted chondrogenesis and trans-differentiation to chondrocytes of the SMCs, a notion supported by aortic media calcification and changes in cultured SMC differentiation and calcification in ank/ank mice [35]. Therefore, acquired regional and systemic decrements in NPP1 and ANK expression and extracellular $\mathrm{PP}_{\mathrm{i}}$ could contribute to intra-arterial chondroosseous metaplasia and calcification in aging, diabetes mellitus, and atherosclerosis. In addition, it is noteworthy that systemic $\mathrm{PP}_{\mathrm{i}}$ deficiency is seen in hemodialysisdependent renal insufficiency, a condition associated with hyperphosphatemia and often extensive artery media and periarticular calcifications [58].

\section{Conclusions and perspectives}

Support of extracellular $\mathrm{PP}_{\mathrm{i}}$ levels by NPP1 and ANK inhibits pathologic soft tissue calcification but supports hard tissue mineralization in long bones and promotes calcification of articular cartilages in aging and $\mathrm{OA} . \mathrm{PP}_{\mathrm{i}}$ is a central regulator of calcification in the extracellular matrix, but extracellular $\mathrm{PP}_{\mathrm{i}}$ regulates gene expression and cellular differentiation, including major physiologic effects on chondrogenesis and expression of osteopontin. The larger significance of mutants of NPP1 and ANK in disease continues to be elucidated. For example, mutants of ANKH, concentrated mainly at the N-terminal end of the molecule, have been linked with both autosomal dominant familial and 'sporadic' CPPD crystal deposition disease of articular cartilage [59, 60]. But other ANKH mutants clustered in putative cytosolic loops well-removed the Nand C-termini are linked with the distinct phenotype of craniometaphyseal dysplasia, a disease mediated by abnormal skeletal remodeling more than pathologic calcification $[61,62]$. Polymorphisms in the human homologue of ANK (ANKH) also appear to contribute to differences in hand bone size and geometry that may influence bone fragility in a homogeneous Chuvasha population [63]. In the same population, NPP1 gene polymorphisms appeared to contribute to variance in severity of hand joint OA [64].

NPP1, in a catalytic activity-independent manner, inhibits ligand-induced insulin receptor signaling [65], an effect that appears linked to NPP1 mutations associated with type II diabetes mellitus in some but not all ethnic groups studied [66, 67]. Interestingly, the K173Q SNP of NPP1, which maps to the second somatomedin-B-like domain of NPP1 and has been linked to insulin resistance, does not modulate NPP1 dimerization or catalytic activity or affect physical interaction of NPP1 with the insulin receptor [68]. Inherited states of putative 'gain-of-function' of NPP1 also have been linked to obesity [69], also likely mediated primarily via effects on insulin receptor signaling. However, it is not likely that the numerous NPP1 catalytic site-independent mutants implicated as interfering with ligand-induced insulin receptor signaling directly affect mineralization.

Last, NPP1 not only generates $\mathrm{PP}_{\mathrm{i}}$ but also modulates $N$ glycosylation and secretion of glycoproteins, and proteoglycans sulfation [6-8], and NPP1 also scavenges ATP and thereby regulates purinergic receptor signaling. The potential roles in calcification of these alternative effects of NPP1, and of other NPP1 interactions with nucleotide- 
hydrolyzing ecto-ezymes, remain to be determined. Nevertheless, the remarkable phenotypic similarities between NPP1-deficient and ANK-deficient mice strongly support the central role of NPP1 catalyzed $\mathrm{PP}_{\mathrm{i}}$ generation in the regulation of calcification.

\section{Acknowledgments}

Our work has is supported by the Department of Veterans Affairs Research Service and by NIH grants HL077360, P01AGO7996, AR049366.

\section{References}

1. Robson SC, Wu Y, Sun X et al. Ectonucleotidases of CD39 family modulate vascular inflammation and thrombosis in transplantation. Semin Thromb Hemost 2005; 31: 217-33.

2. Vorhoff $\mathrm{T}$, Zimmermann $\mathrm{H}$, Pelletier $\mathrm{J}$ et al. Cloning and characterization of the ecto-nucleotidase NTPDase 3 from rat brain: Predicted secondary structure and relation to other members of the E-NTPDase family and actin. Purinergic Signalling 2005; 1: 259-70.

3. Deterre P, Gelman L, Gary-Gouy $\mathrm{H}$ et al. Coordinated regulation in human $\mathrm{T}$ cells of nucleotide-hydrolyzing ecto-enzymatic activities, including $\mathrm{CD} 38$ and $\mathrm{PC}-1$. Possible role in the recycling of nicotinamide adenine dinucleotide metabolites. J Immunol 1996; 157: $1381-8$.

4. Stefan C, Jansen S, Bollen M. NPP-type ectophosphodiesterases: Unity in diversity. Trends Biochem Sci 2005; 30: 542-50.

5. Bello V, Goding JW, Greengrass V et al. Characterization of a dileucine-based signal in the cytoplasmic tail of the nucleotidepyrophosphatase NPP1 that mediates basolateral targeting but not endocytosis. Mol Biol Cell 2001; 12: 3004-15.

6. Hickman S, Wong-Yip YP, Rebbe NF, Greco JM. Formation of lipid-linked oligosaccharides by MOPC 315 plasmacytoma cells. Decreased synthesis by a nonsecretory variant. J Biol Chem 1985; 260: 6098-106.

7. Goding JW, Grobben B, Slegers H. Physiological and pathophysiological functions of the ecto-nucleotide pyrophosphatase/phosphodiesterase family. Biochim Biophys Acta 2003; 1638: 1-19.

8. Goding JW. Ecto-enzymes: Physiology meets pathology. J Leukoc Biol 2000; 67: 285-311.

9. Jansen S, Stefan C, Creemers JW et al. Proteolytic maturation and activation of autotaxin (NPP2), a secreted metastasis-enhancing lysophospholipase D. J Cell Sci 2005; 118: 3081-9.

10. van Meeteren LA, Ruurs P, Christodoulou E et al. Inhibition of autotaxin by lysophosphatidic acid and sphingosine 1-phosphate. J Biol Chem 2005; 280: 21155-61.

11. Cimpean A, Stefan C, Gijsbers R et al. Substrate-specifying determinants of the nucleotide pyrophosphatases/phosphodiesterases NPP1 and NPP2. Biochem J 2004; 381: 71-7.

12. Johnson $\mathrm{K}$, Hashimoto $\mathrm{S}$, Lotz $\mathrm{M}$ et al. Up-regulated expression of the phosphodiesterase nucleotide pyrophosphatase family member PC-1 is a marker and pathogenic factor for knee meniscal cartilage matrix calcification. Arthritis Rheum 2001; 44: 1071-81.

13. Durgam GG, Virag T, Walker MD et al. Synthesis, structure-activity relationships, and biological evaluation of fatty alcohol phosphates as lysophosphatidic acid receptor ligands, activators of PPARgamma, and inhibitors of autotaxin. J Med Chem 2005; 48: 4919-30.

14. Moolenaar WH. Lysophospholipids in the limelight: Autotaxin takes center stage. J Cell Biol 2002; 158: 197-9.

15. Koh E, Clair T, Woodhouse EC et al. Site-directed mutations in the tumor-associated cytokine, autotaxin, eliminate nucleotide phosphodiesterase, lysophospholipase D, and motogenic activities. Cancer Res 2003; 63: 2042-5.
16. Johnson KA, Hessle L, Vaingankar S et al. Osteoblast tissuenonspecific alkaline phosphatase antagonizes and regulates PC-1. Am J Physiol Regul Integr Comp Physiol 2000; 279: R1365-77.

17. Vaingankar SM, Fitzpatrick TA, Johnson K et al. Subcellular targeting and function of osteoblast nucleotide pyrophosphatase phosphodiesterase 1. Am J Physiol Cell Physiol 2004; 286: C1177-87.

18. Johnson K, Goding J, Van Etten D et al. Linked deficiencies in extracellular $\mathrm{PP}_{\mathrm{i}}$ and osteopontin mediate pathologic calcification associated with defective PC-1 and ANK expression. J Bone Miner Res 2003; 18: 994-1004.

19. Terkeltaub $\mathrm{R}$. Inorganic pyrophosphate $\left(\mathrm{PP}_{\mathrm{i}}\right)$ generation and disposition in pathophysiology. Am J Physiol: Cell Physiol 2001; 281: C1-11.

20. Okawa A, Nakamura I, Goto S et al. Mutation in Npps in a mouse model of ossification of the posterior longitudinal ligament of the spine. Nat Genet 1998; 19: 271-3.

21. Hessle L, Johnson KA, Anderson $\mathrm{HC}$ et al. Tissue-nonspecific alkaline phosphatase and plasma cell membrane glycoprotein-1 are central antagonistic regulators of bone mineralization. Proc Natl Acad Sci USA 2002; 99: 9445-9.

22. Ho AM, Johnson MD, Kingsley DM. Role of the mouse ank gene in control of tissue calcification and arthritis. Science 2000; 289: 265-70.

23. Ruf N, Uhlenberg B, Terkeltaub $\mathrm{R}$ et al. The mutational spectrum of ENPP1 as arising after the analysis of 23 unrelated patients with generalized arterial calcification of infancy (GACI). Human Mutat 2005; 25: 98-104.

24. Rutsch F, Ruf N, Vaingankar S et al. Mutations in ENPP1 are associated with 'idiopathic' infantile arterial calcification. Nat Genet 2003; 34: 379-81.

25. Rutsch F, Vaingankar S, Johnson $\mathrm{K}$ et al. PC-1 nucleoside triphosphate pyrophosphohydrolase deficiency in idiopathic infantile arterial calcification. Am J Pathol 2001; 158: 543-54.

26. Rutsch F, Schauerte P, Kalhoff $\mathrm{H}$ et al. Low levels of urinary inorganic pyrophosphate indicating systemic pyrophosphate deficiency in a boy with idiopathic infantile arterial calcification. Acta Paediatr 2000; 89: 1265-9.

27. Anderson HC, Harmey D, Camacho NP et al. Sustained osteomalacia of long bones despite major improvement in other hypophosphatasiarelated mineral deficits in tissue nonspecific alkaline phosphatase/ nucleotide pyrophosphatase phosphodiesterase 1 double-deficient mice. Am J Pathol 2005; 166: 1711-20.

28. Kobayashi $\mathrm{Y}$, Goto S, Tanno $\mathrm{T}$ et al. Regional variations in the progression of bone loss in two different mouse osteopenia models. Calcif Tissue Int 1998; 62: 426-36.

29. Johnson $\mathrm{K}$, Terkeltaub $\mathrm{R}$. Inorganic pyrophosphate $\left(\mathrm{PP}_{\mathrm{i}}\right)$ in pathologic calcification of articular cartilage. Front Biosci 2005; 10: 988-97.

30. Johnson K, Pritzker K, Goding J, Terkeltaub R. The nucleoside triphosphate pyrophosphohydrolase isozyme PC-1 directly promotes cartilage calcification through chondrocyte apoptosis and increased calcium precipitation by mineralizing vesicles. J Rheumatol 2001; 28: 2681-91

31. Johnson K, Vaingankar S, Chen Y et al. Differential mechanisms of inorganic pyrophosphate production by plasma cell membrane glycoprotein-1 and B10 in chondrocytes. Arthritis Rheum 1999; 42: 1986-97.

32. Derfus BA, Kurian JB, Butler JJ et al. The high prevalence of pathologic calcium crystals in pre-operative knees. $\mathrm{J}$ Rheumatol 2002; 29: 570-4.

33. Harmey D, Hessle L, Narisawa $\mathrm{S}$ et al. Concerted regulation of inorganic pyrophosphate and osteopontin by akp2, enpp1, and ank: An integrated model of the pathogenesis of mineralization disorders. Am J Pathol 2004; 164: 1199-209.

34. Johnson K, Terkeltaub R. Upregulated ank expression in osteoarthritis can promote both chondrocyte MMP-13 expression and calcification via chondrocyte extracellular $\mathrm{PP}_{\mathrm{i}}$ excess. Osteoarthritis Cartilage 2004; 12: 321-35.

35. Johnson K, Polewski M, van Etten D, Terkeltaub R. Chondrogenesis mediated by $\mathrm{PP}_{\mathrm{i}}$ depletion promotes spontaneous aortic calcification 
in NPP1-/- mice. Arterioscler Thromb Vasc Biol 2005; 25: 686-91.

36. Wang W, Xu J, Du B, Kirsch T. Role of the progressive ankylosis gene (ank) in cartilage mineralization. Mol Cell Biol 2005; 25: 312-23.

37. Beck GR Jr. Inorganic phosphate as a signaling molecule in osteoblast differentiation. J Cell Biochem 2003; 90: 234-43.

38. Beck GR Jr, Zerler B, Moran E. Phosphate is a specific signal for induction of osteopontin gene expression. Proc Natl Acad Sci USA 2000; 97: 8352-7.

39. Rogers MJ. New insights into the molecular mechanisms of action of bisphosphonates. Curr Pharm Des 2003; 9: 2643-58.

40. Fujita T, Izumo N, Fukuyama R et al. Incadronate and etidronate accelerate phosphate-primed mineralization of MC4 cells via ERK1/ 2-Cbfa1 signaling pathway in a Ras-independent manner: Further involvement of mevalonate-pathway blockade for incadronate. Jpn J Pharmacol 2001; 86: 86-96.

41. Ho AM, Johnson DM. Kingsley: Role of the mouse ank gene in control of tissue calcification and arthritis. Science 2000; 289: 265-70.

42. Kalya S, Rosenthal AK. Extracellular matrix changes regulate calcium crystal formation in articular cartilage. Curr Opin Rheumatol 2005; 17: 325-329.

43. Lotz M, Rosen F, McCabe G et al. Interleukin 1 beta suppresses transforming growth factor-induced inorganic pyrophosphate $\left(\mathrm{PP}_{\mathrm{i}}\right)$ production and expression of the $\mathrm{PP}_{\mathrm{i}}$-generating enzyme $\mathrm{PC}-1$ in human chondrocytes. Proc Natl Acad Sci USA 1995; 92: 10364-8.

44. Rosen F, McCabe G, Quach J et al. Differential effects of aging on human chondrocyte responses to $\mathrm{TGF} \beta$ : Increased pyrophosphate production and decreased cell proliferation. Arthritis Rheum 1997; 40: $1275-81$

45. Johnson K, Jung AS, Andreyev A et al. Mitochondrial Oxidative Phosphorylation is a downstream regulator of nitric oxide effects on chondrocyte matrix synthesis and mineralization. Arthritis Rheum 2000; 43: 1560-70.

46. Murshed M, Harmey D, Millan JL et al. Unique coexpression in osteoblasts of broadly expressed genes accounts for the spatial restriction of ECM mineralization to bone. Genes Dev 2005; 19 : 1093-104.

47. Costello JC, Ryan LM. Modulation of chondrocyte production of extracellular inorganic pyrophosphate. Curr Opin Rheumatol 2004; 16: $268-72$.

48. Johnson K, Svensson CI, Etten DV et al. Mediation of spontaneous knee osteoarthritis by progressive chondrocyte ATP depletion in Hartley guinea pigs. Arthritis Rheum 2004; 50: 1216-25.

49. Masuda I, Halligan BD, Barbieri JT et al. Molecular cloning and expression of a porcine chondrocyte nucleotide pyrophosphohydrolase. Gene 1997; 197: 277-87.

50. Masuda I, Hamada J, Haas AL et al. A unique ectonucleotide pyrophosphohydrolase associated with porcine chondrocyte-derived vesicles. J Clin Invest 1995; 95: 699-704.

51. Hirose J, Masuda I, Ryan LM. Expression of cartilage intermediate layer protein/nucleotide pyrophosphohydrolase parallels the production of extracellular inorganic pyrophosphate in response to growth factors and with aging. Arthritis Rheum 2000; 43: 2703-11.

52. Johnson K, Farley D, Hu SI, Terkeltaub R. One of two chondrocyteexpressed isoforms of cartilage intermediate-layer protein functions as an insulin-like growth factor 1 antagonist. Arthritis Rheum 2003; 48: $1302-14$
53. Nakamura I, Ikegawa S, Okawa A et al. Association of the human NPPS gene with ossification of the posterior longitudinal ligament of the spine (OPLL). Hum Genet 1999; 104: 492-7.

54. Koshizuka Y, Kawaguchi H, Ogata N et al. Nucleotide pyrophosphatase gene polymorphism associated with ossification of the posterior longitudinal ligament of the spine. J Bone Miner Res 2002; 17: 138-44.

55. Tahara M, Aiba A, Yamazaki M et al. The extent of ossification of posterior longitudinal ligament of the spine associated with nucleotide pyrophosphatase gene and leptin receptor gene polymorphisms. Spine 2005; 3: 877-80.

56. Mori $\mathrm{K}$, Chano $\mathrm{T}$, Ikeda $\mathrm{T}$ et al. Decrease in serum nucleotide pyrophosphatase activity in ankylosing spondylitis. Rheumatology (Oxford) 2003; 42: 62-5.

57. Johnson K, Moffa A, Chen $\mathrm{Y}$ et al. Matrix vesicle plasma cell membrane glycoprotein-1 regulates mineralization by murine osteoblastic MC3T3 cells. J Bone Miner Res 1999; 14: 883-92.

58. Lomashvili KA, Khawandi W, O’Neill WC. Reduced plasma pyrophosphate levels in hemodialysis patients. J Am Soc Nephrol 2005; 16: 2495-500.

59. Williams CJ. Familial calcium pyrophosphate dihydrate deposition disease and the ANKH gene. Curr Opin Rheumatol 2003; 15: 326-31.

60. Zhang Y, Johnson K, Russell RG et al. Association of sporadic chondrocalcinosis with a -4 -basepair G-to-A transition in the $5^{\prime}$ untranslated region of ANKH that promotes enhanced expression of ANKH protein and excess generation of extracellular inorganic pyrophosphate. Arthritis Rheum 2005; 52: 1110-7.

61. Reichenberger E, Tiziani V, Watanabe $\mathrm{S}$ et al. Autosomal dominant craniometaphyseal dysplasia is caused by mutations in the transmembrane protein ANK. Am J Hum Genet 2001; 68: 1321-6.

62. Nurnberg $\mathrm{P}$, Thiele $\mathrm{H}$, Chandler $\mathrm{D}$ et al. Heterozygous mutations in $\mathrm{ANKH}$, the human ortholog of the mouse progressive ankylosis gene, result in craniometaphyseal dysplasia. Nat Genet 2001; 28: $37-41$.

63. Malkin I, Dahm S, Suk A et al. Association of ANKH gene polymorphisms with radiographic hand bone size and geometry in a Chuvasha population. Bone 2005; 36: 365-73.

64. Suk EK, Malkin I, Dahm S et al. Association of ENPP1 gene polymorphisms with hand osteoarthritis in a Chuvasha population. Arthritis Res Ther 2005; 7: R1082-90.

65. Dong H, Maddux BA, Altomonte J et al. Increased hepatic levels of the insulin receptor inhibitor, PC-1/NPP1, induce insulin resistance and glucose intolerance. Diabetes 2005; 54: 367-72.

66. Morrison JA, Gruppo R, Glueck CJ et al. Population-specific alleles: The polymorphism (K121Q) of the human glycoprotein PC-1 gene is strongly associated with race but not with insulin resistance in black and white children. Metabolism 2004; 53: 465-8.

67. Gijsbers R, Ceulemans H, Bollen M. Functional characterization of the non-catalytic ectodomains of the nucleotide pyrophosphatase/ phosphodiesterase NPP1. Biochem J 2003; 371: 321-30.

68. Stefanovic V, Antic S. Plasma cell membrane glycoprotein 1 (PC-1): A marker of insulin resistance in obesity, uremia and diabetes mellitus. Clin Lab 2004; 50: 271-8.

69. Meyre D, Bouatia-Naji N, Tounian A et al. Variants of ENPP1 are associated with childhood and adult obesity and increase the risk of glucose intolerance and type 2 diabetes. Nat Genet 2005; 37: 863-7. 